\title{
HUBUNGAN TINGKAT AKTIVITAS EKSTRAKURIKULER TERHADAP TINGKAT KECEMASAN ANAK USIA SEKOLAH DASAR
}

\author{
Ilma Hanifah \\ Fakultas Kedokteran, Universitas Muahmmadiyah Malang \\ J1. Bendungan Sutami 188 A Malang, 65145
}

Email : hanifah.ilma@gmail.com

\begin{abstract}
ABSTRAK
Anak-anak masa kini memiliki waktu bermain delapan jam lebih sedikit dibandingkan dua puluh tahun lalu dikarenakan aktivitas di luar jam sekolah yang padat. Salah satu akibatnya adalah muncul tanda-tanda kecemasan. Dari penelitian sebelumnya didapatkan siswa yang mengikuti banyak aktivitas di luar jam sekolah muncul adanya tanda-tanda kecemasan seperti jantung berdebar kencang dan keras (46,7\%), merasa sukar berkonsentrasi pada saat melakukan kegiatan $(43,3 \%)$ dan merasa sangat lemas/lesu/tidak memiliki tenaga (43,3\%) dibandingkan dengan siswa yang tidak mengikuti banyak aktivitas di luar jam sekolah. Penelitian ini bertujuan untuk mengetahui hubungan tingkat aktivitas ekstrakurikuler terhadap tingkat kecemasan anak usia sekolah dasar. Metode yang digunakan dalam penelitian ini adalah observasional analitik dengan desain cross sectional. Kuesioner yang digunakan adalah kuesioner Revised Children's Manifest Anxiety Scale (RCMAS). Analisis hubungan dilakukan dengan menggunakan uji komparasi Kruskal Wallis dan Mann-Whitney. Hasil penelitian menunjukkan sebanyak 56\% responden memiliki tingkat aktivitas ekstrakurikuler tinggi. Responden yang mengalami kecemasan, sebanyak $27 \%$, memiliki tingkat aktivitas ekstrakurikuler tinggi. Ekstrakurikuler terbanyak yang diikuti adalah tambahan mata pelajaran (53\%).
\end{abstract}

Kata kunci: Tingkat ekstrakurikuler, tingkat kecemasan, anak

\section{ABSTRACT}

Children's nowadays have play time eight hours less than twenty years ago as the result of so many afterschool activities. This many afterschool activities causes anxiety. Previous research found that this many afterschool activities makes children suffering from anxiety that shows fast heart beating (46,7\%), difficult to concentrate when doing activities (43,3\%) and feel very letabrgic (43,3\%) compared with children who don't have those activities. Objective from this experiment is to find out the correlation between the level extracurricular activities and the anxiety level among cbildren of elementary school. This study applied an observational research using cross sectional analysis. The quationnaire that used was Revised Children's Manifest Anxiety Scale (RCMAS) questionnaire. Analysis of correlation was tested by comparison test of Kruskal Wallis and Mann-Whitney. The result of the research showed that fifty-six percent of respondents have bigh level of extracurricular activities. Respondents who experienced anxiety (27\%) have bigh level of extracurricular activities.

Keyword: Extracurricular, anxiety, children 


\section{LATAR BELAKANG}

Perasaan cemas tampaknya sudah menjadi bagian dari kehidupan. Hal ini dapat dialami hampir setiap orang pada waktu tertentu dalam kehidupannya. Kecemasan akan timbul jika individu tidak mampu menghadapi suatu keadaan stres, di mana stres dapat mengancam perasaan dan kemampuan hidupnya (Maramis WF, 2005). Stres dan kecemasan ini menjadi perhatian utama ketika telah mempengaruhi fungsi normal seseorang dalam kehidupannya sehari-hari (Wibisono, 2003)

Kecemasan dapat dialami oleh setiap orang, tidak hanya melanda orang dewasa, anak-anak dapat mengalami rasa cemas dikarenakan kegiatan sehari-harinya, terutama yang telah memasuki usia sekolah. Cemas saat pertama kali masuk sekolah, perpisahan dengan orang tua, banyaknya tugas atau beratnya beban dalam meningkatkan prestasi belajar anak dapat membuat anak stres hingga menimbulkan kecemasan (Widyastuti R, 2009).

Dewasa ini banyak orang tua yang menginginkan anak-anaknya ikut serta dalam berbagai kursus. David Elkind, psikolog Amerika, memperkenalkan sebuah istilah baru yaitu Hurried Child Syndrome yang menggambarkan suatu fenomena anak yang dipercepat perkembangannya dan mereplika kehidupan orang dewasa yang sibuk dan sangat terjadwal. Aktivitas-aktivitas yang diikuti tersebut diarahkan oleh orang tua, bukan sekedar untuk mencari kesenangan, namun untuk pencapaian tertentu yang diinginkan orang tuanya (Gross Gail. 2013. Pranadji DK \& Nurlaela, 2009). Dalam sebuah seri infographic "The Science of Raising Happy Kids", dikatakan anak-anak masa kini memiliki waktu bermain delapan jam lebih sedikit dibandingkan dua puluh tahun lalu. Hal ini dikarenakan jadwal mereka yang padat dengan aktivitas ekstrakurikuler dan les sepulang sekolah, sehingga kehilangan sebagian waktu bermain bebasnya.

Pada penelitian Pranadji DK \& Nurlaela (2009) menunjukkan bahwa pada siswa yang sibuk muncul adanya tanda-tanda seperti jantung berdebar kencang dan keras $(46,7 \%)$, merasa sukar berkonsentrasi pada saat melakukan kegiatan $(43,3 \%)$ dan merasa sangat lemas/lesu/tidak memiliki tenaga (43,3\%) dibandingkan dengan siswa yang tidak sibuk dilihat dari alokasi waktu dan jumlah aktivitas di luar sekolah yang diikuti. Pada penelitian Al Jannah (2016) menunjukkan bahwa terdapat hubungan antara kegiatan ekstrakurikuler dengan tingkat stres pada siswi di Madrasah 'Aliyah Mu'allimaat Muhammadiyah Yogyakarta.

Berdasarkan fenomena tersebut, peneliti merasa pentingnya penelitian yang mempelajari tingkat kecemasan yang dialami anak usia sekolah dasar berdasarkan tingkat aktivitas ekstrakurikuler yang diikutinya.

\section{TINJUAN PUSTAKA}

Berdasarkan Peraturan Menteri Pendidikan dan Kebudayaan Republik Indonesia Nomor 62 Tahun 2014 tentang kegiatan ekstrakurikuler pada pendidikan dasar dan pendidikan menengah, kegiatan ekstrakurikuler adalah kegiatan kurikuler yang dilakukan oleh peserta didik di luar jam belajar kegiatan intrakurikuler dan kegiatan kokurikuler, di bawah bimbingan dan pengawasan satuan pendidikan. Kegiatan ekstrakurikuler ditujukan agar siswa dapat mengembangkan kepribadian, bakat, dan kemampuannya di berbagai bidang di luar akademik (Susanti YD, 2012, Hurlock E, 2002)

Kecemasan sebagai keadaan yang emosional yang mempunyai ciri keterangsangan fisiologis, perasaan yang tegang yang tidak menyenangkan dan perasaan aprehensi atau keadaan khawatir yang mengeluhkan bahwa sesuatu yang buruk akan segera terjadi (Nevid JS, Spencer A, Beverly G, 2005, Kaplan HI, Sadock BJ, Grebb JA, 2010).

Seorang anak yang mengalami situasi mengancam atau merasa cemas, perilaku motornya akan berupaya menarik diri, menghindar atau menghadapi stresor yang dialami. Individu dapat merasa gelisah, kesulitan duduk diam, otot-otot terasa tegang. Selain itu, respon perilaku dapat berupa bicara cepat, cepat marah, irasional bahkan perilaku agresif. Individu juga mengalami respon somatik atau fisiologis. Respon fisiologis dapat dianggap sebagai respon "fight or flight" dan mempersiapkan tubuh untuk mengambil tindakan dalam merespon stresor. Respon fisiologis tersebut termasuk ketegangan otot, keringat berlebih, napas cepat atau dangkal, peningkatan detak jantung dan tekanan darah. Respon fisiologis lain dapat berupa gejala fisik negatif seperti sakit kepala, sakit perut, pusing, kesulitan tidur, serta gangguan pencernaan seperti mual dan muntah (American Psychological Association, 2000) 
Allen \& Klein (dalam Kusz, 2009) mengatakan bahwa hasil utama dari paparan stresor yang kronis adalah kecemasan. Kecemasan dapat dilihat dari rasa takut ketika tidak ada bahaya fisik yang terlihat. Kecemasan dapat dilihat menjadi dua kategori berbeda, yaitu kecemasan umum dan kecemasan situasional. Kecemasan umum biasanya sesuatu yang dipelajari pada masa kanak-kanak dan menjadi bagian dari gaya hidup seseorang. Kecemasan situasional ini terkait dengan aktivitas atau kejadian tertentu. Terlalu sering dengan kecemasan situasional ini terkadang dapat membentuk menjadi kebiasaan.

Anak dengan banyak kesibukan mempunyai insiden lebih tinggi mengalami kecemasan khususnya kecemasan performa. Mereka memikirkan bagaimana cara melakukan kegiatan-kegiatan tersebut dan memperjuangkan agar dapat melampaui target. Kebanyakan tanda-tanda depresi dilihat penarikan dari teman-teman dan keluarga, merasa buruk tentang dirinya. Menjadi sibuk dan stres dapat juga berdampak pada fungsi dasar anak seperti gangguan tidur dan perubahan pola makan. Beberapa anak mulai menunjukkan tanda seperti sakit kepala, sakit perut, dan tidak mau pergi sekolah atau ikut kegiatan. Beberapa aktivitas, jika tetap seimbang akan sangat bermanfaat untuk keterampilan sosial, hobi dan pengembangan minat anak (Kobylinski Heather. 2004)

Penelitian menunjukkan kecemasan yang paling umum terkait gejala somatik atau fisiologis yang dialami anak-anak adalah sakit kepala, diikuti mual, sakit perut, pusing, sesak napas, dan detak jantung meningkat (Muris P \& Meesters C, 2004).

Sekolah perlu melihat penyebab stres anak di usia sekolah dasar dan cara untuk meringankan stres dan cemas tersebut. Sekolah juga dapat ikut mengedukasi orang tua serta masyarakat umum bagaimana membantu generasi dengan kecemasan yang tinggi ini (Kusz ML, 2009)

\section{METODE PENELITIAN}

Penelitian ini yang menggunakan jenis penelitian observasi analitik dengan desain cross sectional. Proses pengambilan data dilaksanakan pada bulan Februari hingga Maret 2017 terhadap siswa kelas V di SD Negeri Kauman 1 Malang sejumlah 68 responden. Responden tersebut melengkapi informed consent, identitas, daftar ekstrakurikuler dan kuesioner Revised Children's Manifest Anxiety Scale (RCMAS). Analisis hubungan dilakukan dengan menggunakan uji komparasi Kruskal Wallis dan Mann-Whitney.

\section{HASIL DAN PEMBAHASAN}

Berdasarkan hasil penelitian yang telah dilakukan, didapatkan bahwa persentase tingkat kecemasan didapatkan anak usia sekolah dasar sebesar 27\% mengalami kecemasan dan sisanya tidak mengalami kecemasan. Hasil penelitian ini tidak jauh berbeda dengan hasil penelitian Harwanto NC, Fitrikasari A \& Sarjana W (2015) dimana distribusi kejadian kecemasan pada responden, yang pada penelitian ini adalah remaja SMA, sebesar 24,6\% mengalami kecemasan (Harwanto NC, Fitrikasari A, Sarjana W, 2015) Menurut Allen \& Klein (dalam Kusz, 2009) mengatakan bahwa kecemasan adalah hasil utama dari paparan stresor yang kronis. Pada penelitian Al Jannah (2016), dikatakan bahwa perasaan seperti cemas, mudah gelisah, mudah tersinggung, mudah marah merupakan beberapa gejala dari stres yang dialami individu. Persepsi atau kadar stres yang dialami individu bergantung pada bagaimana individu bereaksi terhardap stres tersebut (Al Jannah PR, 2016)

Jumlah responden yang mengalami kecemasan sebesar 18 responden, diketahui bahwa sebagian besar memilih ekstrakurikuler atas keinginannya sendiri yaitu sebesar 75,3\% dan sisanya dipilihkan oleh orang tua. Hal ini berlawanan dengan teori Ruffin (2001) bahwa kecemasan orang tua akan prestasi anak kemudian membuat anak diberi berbagai kursus tanpa memperhitungkan waktu untuk bermain dan bersosialisasi, sehingga membuat anak merasa jenuh dengan rutinitasnya dan prestasi menjadi menurun (Ruffin NJ, 2001)

Persentase tingkat ekstrakurikuler menunjukkan bahwa sebagian besar responden memiliki tingkat ekstrakurikuler tinggi (e"7 jam per minggu). Pada penelitian ini, alokasi waktu aktivitas ekstrakurikuler tinggi per minggu adalah sebesar 12,9 jam, sedang 5,8 jam dan rendah 2,8 jam. Hasil penelitian ini lebih tinggi jika dibandingkan dengan penelitian Pranadji DK \& Nurlaela (2009) alokasi waktu untuk kegiatan di luar sekolah sebesar 7,8 jam per minggu bagi anak yang sibuk, sedangkan 
bagi anak yang tidak sibuk sebesar 2,1 jam per minggu.

Distribusi jenis ekstrakurikuler yang diikuti anak usia sekolah dasar didapatkan sebagian besar mengikuti tambahan mata pelajaran setiap minggunya sebesar 53\%. Tambahan mata pelajaran ini diikuti oleh beberapa besar responden di luar sekolah seperti les di bimbel maupun privat, dan sebagian kecil lainnya mengikuti di sekolah sebagai ekstrakurikuler pilihan. Hasil penelitian ini juga tidak jauh berbeda dengan penelitian Harwanto NC, Fitrikasari A \& Sarjana W (2015), dimana pada karakteristik responden sebagian besar responden mengikuti les akademik (56,5\%) dibandingkan dengan les non akademik (26,1\%).

Berdasarkan penelitian ini, didapatkan bahwa ada perbedaan yang signifikan antara tingkat aktivitas ekstrakurikuler di luar jam sekolah dengan tingkat kecemasan anak usia sekolah dasar. Hasil penelitian ini sejalan dengan penelitian Pranadji DK \& Nurlaela (2009), bahwa semakin meningkat jenis, jumlah dan alokasi waktu kegiatan di luar sekolah akan meningkatkan tingkat stres pada anak usia sekolah dasar. Jika pada penelitian tersebut gejala yang seringkali dialami oleh sebagian besar responden adalah jantung berdebar kencang dan keras (46,7\%), susah berkonsentrasi pada saat melakukan kegiatan $(43,3 \%)$ dan merasa sangat lemas/lesu/tidak memiliki tenaga (43,3\%). Pada penelitian ini, sebagian besar responden sering merasa tidak tenang/gelisah $(79,4 \%)$, sering merasa kelelahan saat melakukan kegiatan (69,1\%), merasa orang lain melakukan sesuatu lebih mudah daripada yang dirinya kerjakan $(60,3 \%)$.

Pada penelitian ini, responden dibagi menjadi 3 kelompok, yaitu kelompok dengan tingkat aktivitas ekstrakurikuler tinggi (e"7 jam per minggu), sedang (3-7 jam per minggu) dan rendah (d"3 jam per minggu), kemudian didapatkan bahwa tidak adanya perbedaan tingkat kecemasan pada kelompok aktivitas ekstrakurikuler rendah dan sedang. Perbedaan signifikan tingkat kecemasan terlihat pada kelompok aktivitas ekstrakurikuler rendah dan tinggi, begitu pula pada kelompok tingkat ekstrakurikuler sedang dan tinggi juga didapatkan adanya perbedaan signifikan. Hal ini menunjukkan bahwa kelompok dengan tingkat aktivitas ekstrakurikuler rendah dan sedang tidak mempengaruhi tingkat kecemasan. Tingkat kecemasan yang dipengaruhi oleh peningkatan aktivitas ekstrakurikuler yaitu pada kelompok dengan tingkat aktivitas ekstrakurikuler tinggi. Selisih alokasi waktu antara tingkat ekstrakurikuler tinggi dengan rendah dan sedang memang terpaut cukup jauh hingga 7-10 jam. Hasil penelitian ini sejalan dengan penelitian Pranadji DK \& Nurlaela (2009), bahwa peningkatan alokasi waktu untuk kegiatan di luar sekolah dapat meningkatkan tingkat stres.

Sebagian besar anak memilih ekstrakurikuler sesuai dengan keinginannya namun beberapa masih mengalami gejala kecemasan dikarenakan jadwal yang terlalu padat dengan alokasi waktu ekstrakurikuler yang tinggi hingga 12,9 jam per minggunya, sehingga anak kesulitan membagi waktu antara aktivitas ekstrakurikuler, kegiatan belajar di rumah dan juga bermain. Ketidakmampuan anak untuk membagi waktu ini dapat memicu stres dimana hipotalamus akan merespon dengan merangsang pengeluaran kortisol dan aktivasi sistem saraf simpatis sehingga menimbulkan beberapa gejala kecemasan. Menurut Oktamiati (2013) jika tidak dicegah, anak bisa mengalami stres karena kegiatan sehari-harinya. Banyaknya tugas, beratnya beban untuk meningkatkan prestasi belajar dan rasa tertekan menimbulkan dampak negatif pada anak, baik secara fisik maupun psikis (Oktamiati Hesi, 2013)

Selain itu pada penelitian Harwanto NC, Fitrikasari A \& Sarjana W (2015), dikatakan bahwa selain karena stresor, kurangnya kemampuan dalam melakukan manajemen stres juga menjadi penyebab munculnya kecemasan. Pada penelitian tersebut manajemen stres terbukti menurunkan gejala kecemasan dan depresi kelompok eksperimen pada pengukuran post-test. Begitu pula pada penelitian Pranadji DK \& Nurlaela (2009) dikatakan bahwa peningkatan alokasi waktu menonton televisi dapat menurunkan tingkat stres, selain itu semakin baik persepsi anak terhadap aktivitas di luar sekolah, maka tingkat stresnya akan semakin menurun.

Keterbatasan penelitian ini yaitu tidak mengelompokkan masing-masing sampel yang bisa menjadi variabel perancu, misalnya pengelompokan menurut pendidikan orang tua, persepsi anak, alokasi waktu bermain sehingga tidak dapat dilakukan pemeriksaan faktor apakah juga berpengaruh terhadap tingkat kecemasan anak. 


\section{VOLUME 12 NOMOR 2 DESEMBER 2016}

\section{KESIMPULAN DAN SARAN}

Terdapat hubungan antara tingkat aktivitas ekstrakurikuler terhadap tingkat kecemasan anak usia sekolah dasar. Sebesar 27\% responden mengalami kecemasan. Sebagian besar responden memiliki tingkat aktivitas ekstrakurikuler yang tinggi sebesar 12,9 jam per minggu. Tingkat kecemasan pada kelompok dengan tingkat aktivitas ekstrakurikuler tinggi memiliki perbedaan signifikan dibandingkan tingkat rendah dan sedang. Jenis kegiatan terbanyak yang diikuti anak usia sekolah dasar di luar jam sekolah adalah tambahan mata pelajaran baik di sekolah maupun di luar sekolah.

Saran yang dapat diberikan perbaikan di masa yang akan datang yaitu sebagai berikut:

\section{Untuk penelitian selanjutnya}

Perlu ditelitinya faktor-faktor perancu yang dapat mempengaruhi tingkat kecemasan anak seperti pendidikan orang tua, persepsi anak, alokasi waktu bermain.

\section{Untuk masyarakat}

Orang tua sebaiknya lebih memperhatikan jumlah ekstrakurikuler yang diikuti anak dan disesuaikan dengan beban sekolahnya, serta anak diberi pengertian mengenai tujuan kegiatan tersebut dan tidak memaksa maupun menekan.

3. Untuk sekolah

Pihak sekolah dapat lebih memperhatikan jumlah kegiatan yang diikuti oleh siswa dan mengadakan konsultasi sebelum dilakukan pemilihan kegiatan.

\section{DAFTAR PUSTAKA}

Al Jannah PR, 2016, Hubungan Kegiatan Ekstrakurikuler dengan Tingkat Stres pada Siswi di Madrasah 'Aliyah Mu'allimat Muhammadiyah Yogyakarta, S1 Skripsi, Fakultas Ilmu Kesehatan Universitas 'Aisyiyah Yogyakarta

American Psychological Association, 2000, Diagnostic and Statistical Manual of Mental Disorders (4th ed., text revision). Washington DC, American Psychological Association

Gross Gail. 2013. The Effect of Hurrying Children Trough Childhood, viewed 11 Februari 2016. $<$ http://www.huffingtonpost.com/dr-gail- gross/the-effects-of-hurrying-childrenthrough-childhood_b_3824197.html>

Harwanto NC, Fitrikasari A, Sarjana W, 2015, Hubungan Prestasi Remaja SMA yang Dikonsulkan ke Bimbingan dan Konseling dengan Kejadian Kecemasan, Media Medika Muda Vol. 4 No. 4 Oktober 2015: 12861294

Hurlock E, 2002, Perkembangan Fisik, Motorik, Emosi, Sosial, In: Tjandrasa M, Zarkasih M (eds), Perkembangan Anak Edisi ke-11 Jilid 2, Erlangga, Jakarta, pp 139-182

Kaplan HI, Sadock BJ, Grebb JA, 2010, Gangguan Ansietas, In: Profitasari \& Nisa TM (eds), Sinopsis Psikiatri Edisi 7 Jilid I, Binarupa Aksara, Jakarta, pp. 230-267

Kobylinski Heather. 2004. Overschedule Children?. Municipal Alliance Committee Helping Hand Vol. 17, Issue 6

Kusz ML, 2009, Stress in Elementary Children, MA Thesis, Nothern Michigan University, Michigan

Maramis WF, 2005, Catatan Ilmu Kedokteran Jiwa, Airlangga University Press, pp. 63-69

Muris P \& Meesters C, 2004, Children's Somatization Symptoms: Correlations with Trait Anxiety, Anxiety Sensitivity, and Learning Experiences. Psychological Reports 94:1269-1275

Nevid JS, Spencer A, Beverly G, 2005, Psikologi Abnormal Edisi ke-5 Jilid 1, Erlangga, Jakarta, pp 134-161

Oktamiati Hesi, 2013, Tingkat Stres Akademik Anak Usia Sekolah Terhadap Sistem Full Day School di Sekolah Dasar Kab. Bogor, S1 Skripsi, Fakultas Ilmu Keperawatan Universitas Indonesia

Pranadji DK \& Nurlaela, 2009, Faktor-faktor yang Mempengaruhi Tingkat Stres pada Anak Usia Sekolah Dasar yang Sibuk dan Tidak Sibuk. Jurnal Ilmu Keluarga dan Konsumen, Vol. 2 No.1:57-63

Ruffin NJ, 2001, Children and Stress: Caring Strategies to Guide Children, viewed 1 April 2017 http://www.ext.vt.edu/pubs/family/ 350-054/350-054.html

15. Susanti YD, 2012, Pelaksanaan Pembelajaran Ekstrakulikuler Melukis di SD Muhammadiyah I Malang, viewed 
http://jurnal-online.um.ac.id/data/artikel/ artikelE06D32E1E85FDB4505EE4B0CBBDB592Dpdf

Wibisono, 2003, Teori Kecemasan, EGC, Jakarta, pp 43-46

Widyastuti R, 2009, Efektivitas Brain Gym Dalam Menurunkan Stres, Jurnal Kesehatan Vol. 2 No. 2:137-146 